\title{
Canadian guidelines for body weight classification in adults: application in clinical practice to screen for overweight and obesity and to assess disease risk
}

Cince 1985 , the number of $\checkmark$ obese adults in Canada has doubled. ${ }^{1}$ According to 2003 data from Statistics Canada (www.statcan.ca/english/freepub /82-221-XIE/00604/tables/html /1228_03.htm), 15\% of adults are obese (body mass index $[\mathrm{BMI}]>30 \mathrm{~kg} / \mathrm{m}^{2}$ ) and $33 \%$ are overweight (BMI 25-29.9 kg/ $\mathrm{m}^{2}$ ) and at increased risk of becoming obese. Given the alarming increase in the prevalence and potential health consequences of obesity, screening for overweight and obesity should be considered an integral part of a routine health assessment.

In 2003, Health Canada published the Canadian Guidelines for Body Weight Classification in Adults (available at www.hc-sc .gc.ca/hpfb-dgpsa/onpp-bppn/cg _bwc_introduction_e.html) to provide a framework for screening people for overweight and obesity. In this article we outline how this new weight classification can be applied to adult men and women (nonpregnant and nonlactating) between the ages of 18 and 65 .

\section{Why is screening important?}

Obese people are at increased risk of diseases such as type 2 diabetes mellitus, hypertension, dyslipidemia, coronary artery disease, stroke, sleep apnea, osteoarthritis, gallstones, stress incontinence, depression and certain types of cancer.

Screening for overweight and obesity may change patient care in 3 ways. First, in adults who are found to be obese and also have obesity-related diseases, modest weight loss (5\%-10\% of total body weight) may improve control of these diseases. For example, weight loss in obese adults with type 2 diabetes and hypertension may improve glycemic and blood pressure control and reduce drug therapy requirements. Second, in adults who are found to be obese but do not have obesity-related diseases, lifestyle interventions (e.g., starting an exercise program) may reduce the risk of these diseases. Third, in adults who are found to be overweight but are otherwise healthy, promoting healthy lifestyle practices may prevent them from becoming obese.

\section{What are the methods for screening?}

$\mathrm{BMI}$ and waist circumference are the 2 measures currently used to screen for overweight and obesity and to assess a person's risk of health problems (Table 1). The $\mathrm{BMI}$ is strongly correlated with reference measures of body fat (e.g., underwater weighing) and is an indicator of risk of weightrelated diseases in men and women. The waist circumference measures abdominal (central) body fat and is strongly correlated with risk of health problems (type 2 diabetes, hypertension, dyslipidemia and the metabolic syndrome, which combines all 3 of these conditions).

\section{What are some practical considerations?}

Measuring the BMI and waist circumference: The BMI and waist circumference are simple, easyto-use measures of adiposity. The correct way to measure the $\mathrm{BMI}$ is shown in Fig. 1, which also provides a BMI reference chart. The correct way to measure waist circumference is shown in Fig. 2.

Considering both measurements to assess disease risk: Although the $\mathrm{BMI}$ and waist circumference are related, the latter provides an in- dependent estimate of health risk beyond that determined by the BMI. It is particularly useful to consider both measures when assessing a patient's disease risk (Fig. 3). For example, in a person with a normal BMI, an increased waist circumference may indicate an abdominal body fat distribution and an increased risk of health problems. ${ }^{2}$ The effect of waist circumference on disease risk in the approximately $10 \%$ of adults who have an extreme BMI $\left(\geq 35 \mathrm{~kg} / \mathrm{m}^{2}\right.$ or $\left.<18.5 \mathrm{~kg} / \mathrm{m}^{2}\right)$ is not provided, because the current waist circumference classification does not provide information about disease risk in such adults. Table 2 presents data from a large, population-based cohort study in the United States that provides estimates of disease risk when waist circumference is added to BMI. ${ }^{2}$ For example, among men and women with a normal BMI, an increased waist circumference appears to confer about a 2-fold increase in risk for some diseases. Among those with a BMI of $30-34.9 \mathrm{~kg} / \mathrm{m}^{2}$, an increased waist circumference con-

Table 1: Body weight classification and risk of health problems by BMI and waist circumference

\begin{tabular}{|c|c|c|}
\hline Measure & $\begin{array}{c}\text { Weight } \\
\text { classification }\end{array}$ & $\begin{array}{l}\text { Risk of health } \\
\text { problems }\end{array}$ \\
\hline \multicolumn{3}{|l|}{ BMI, kg/m² } \\
\hline$<18.5$ & Underweight & Increased \\
\hline $18.5-24.9$ & Normal weight & Least \\
\hline $25.0-29.9$ & Overweight & Increased \\
\hline$\geq 30.0$ & Obese & \\
\hline $30.0-34.9$ & Class I & High \\
\hline $35.0-39.9$ & Class II & Very high \\
\hline$\geq 40.0$ & Class III & Extremely high \\
\hline \multicolumn{3}{|c|}{ Waist circumference } \\
\hline \multicolumn{3}{|l|}{ Men } \\
\hline$<102 \mathrm{~cm}(40 \mathrm{in})$ & & Lower \\
\hline$\geq 102 \mathrm{~cm}$ (40 in) & & Increased \\
\hline \multicolumn{3}{|l|}{ Women } \\
\hline$<88 \mathrm{~cm}$ (35 in) & & Lower \\
\hline$\geq 88 \mathrm{~cm}$ (35 in) & & Increased \\
\hline
\end{tabular}




\section{Practice}

fers a greater than 14-fold increased risk for certain diseases among women but a lesser increase in risk among men. These examples are not necessarily what may be seen in other populations.

Incorporating BMI and waist circumference into an overall risk assessment: The BMI and waist circumference classifications are derived from health risk assessments in large, heterogeneous populations, and consequently the application of BMI and waist circumference to assess the overall risk of health problems in individual patients will vary from person to person and will depend on the presence of other factors that may influence risk. The BMI and waist circumference should be combined with other determinants of risk (e.g., smoking, concomitant disease, diet, physical activity, and personal and family weight history) to estimate overall disease risk.
For example, physical inactivity is a contributor to all-cause mortality and cardiovascular mortality, irrespective of BMI. ${ }^{3}$ What may be underappreciated is the importance of BMI and waist circumference compared with the other, more traditional, risk factors. Until recently, obesity was considered to increase the risk of coronary artery disease through its association with hypertension, dyslipidemia and diabetes. However, a BMI of

- Weight and height are required to measure a person's BMI, which is calculated by dividing weight (kilograms) by height (metres squared).

- Weight is measured with the patient wearing light clothing and no footwear and is recorded to the nearest $0.2 \mathrm{~kg}(1 / 2 \mathrm{lb})$.

- Height is measured with the person wearing no shoes, standing in an erect position, looking straight ahead with feet together and heels against a wall or measuring board. A horizontal bar or another similar device should be lowered so that it rests flat on the top of the person's head. Height is recorded to the nearest $0.5 \mathrm{~cm}(1 / 4 \mathrm{inch})$.

- For a quick determination of BMI, use a straight-edge to help locate the point on the chart below where height (in centimetres or inches) and weight (in kilograms or pounds) intersect. Read the number on the dashed line closest to this point. For example, a person who weighs $69 \mathrm{~kg}$ and is $173 \mathrm{~cm}$ tall has a BMI of about 23.

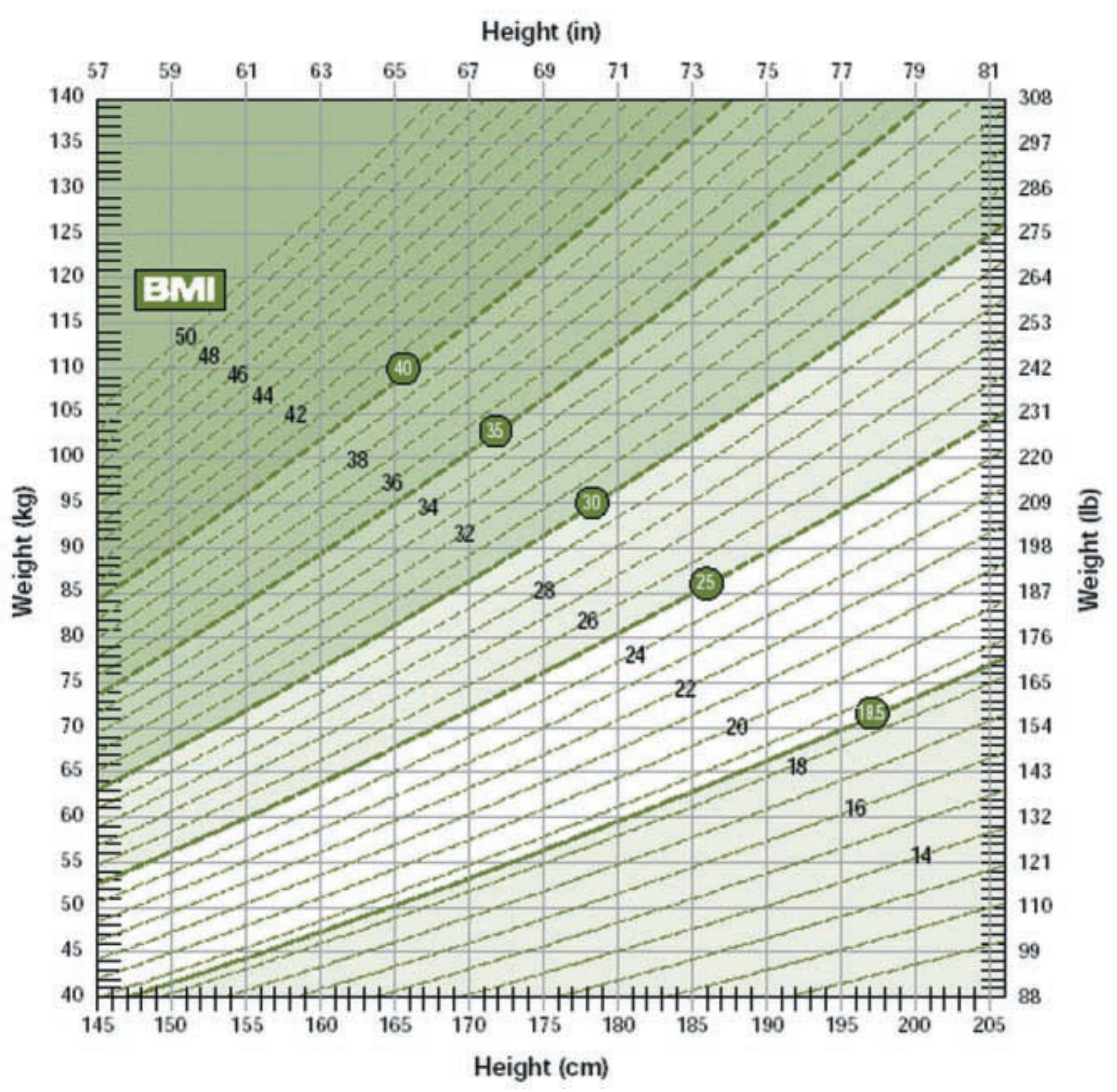

Note: The BMI cannot be used to distinguish between increased body weight due to adiposity or fluid retention (e.g., peripheral edema), although this distinction should be apparent clinically. The BMI may have limitations in people who are very muscular or very lean, in those who are very tall or very short, in people with long limb lengths relative to trunk size (e.g., those with Marfan syndrome) and in people with short limb lengths relative to trunk size (e.g., those with achondroplasia).

Fig. 1: Measuring body mass index (BMI). 
$30 \mathrm{~kg} / \mathrm{m}^{2}$ or greater is an independent risk factor for coronary artery disease, conferring a 2- to 4-fold increase in disease risk, which is comparable to the effect of hypertension on risk of coronary artery disease. ${ }^{4}$

Monitoring BMI and waist circumference over time: The BMI and waist circumference reflect a person's risk status at a single time point. The pattern of BMI and waist circumference over the long term may provide additional information. For example, upward trends in the BMI and waist circumference in people with impaired glucose tolerance may indicate an increased risk of type 2 diabetes. Conversely, downward trends in BMI and waist circumference with unintentional weight loss may indicate an increased risk of disease such as occult cancer.

Weight loss interventions: The need for weight loss interventions should be determined not only on the basis of a person's BMI and waist circumference, but also on the presence or absence of concomitant disease and other patient characteristics. In obese adults with obesityrelated diseases such as type 2 diabetes, the goal may be modest weight loss $(5 \%-10 \%$ body weight) and lifestyle interventions to improve glycemic and blood pressure control and to reduce the risk of myocardial infarction and stroke. On the other hand, in otherwise healthy obese adults, the weight management goal may be to prevent further weight gain and obesityrelated diseases through lifestyle interventions alone.

\section{In what groups may the BMI and waist circumference} classification not be applicable?

Elderly people: Interpreting the $\mathrm{BMI}$ and waist circumference in elderly patients requires caution. People aged 65 years or older who are overweight may not be at increased risk of health problems, whereas those who have a BMI in the low end of the normal range (between $18.5 \mathrm{~kg} / \mathrm{m}^{2}$ and the low $20 \mathrm{~s}$ ) may be at increased risk. Thus, the normal-weight or low-risk $\mathrm{BMI}$ range may be higher and wider (e.g., 22-29 kg/m²) for elderly people than the range for younger adults (18.5-24.9 people, especially loss of fatfree mass, regardless of the baseline BMI, is associated with an increased risk of death. Consequently, screening for weight $\left.\mathrm{kg} / \mathrm{m}^{2}\right)$. Weight loss in elderly

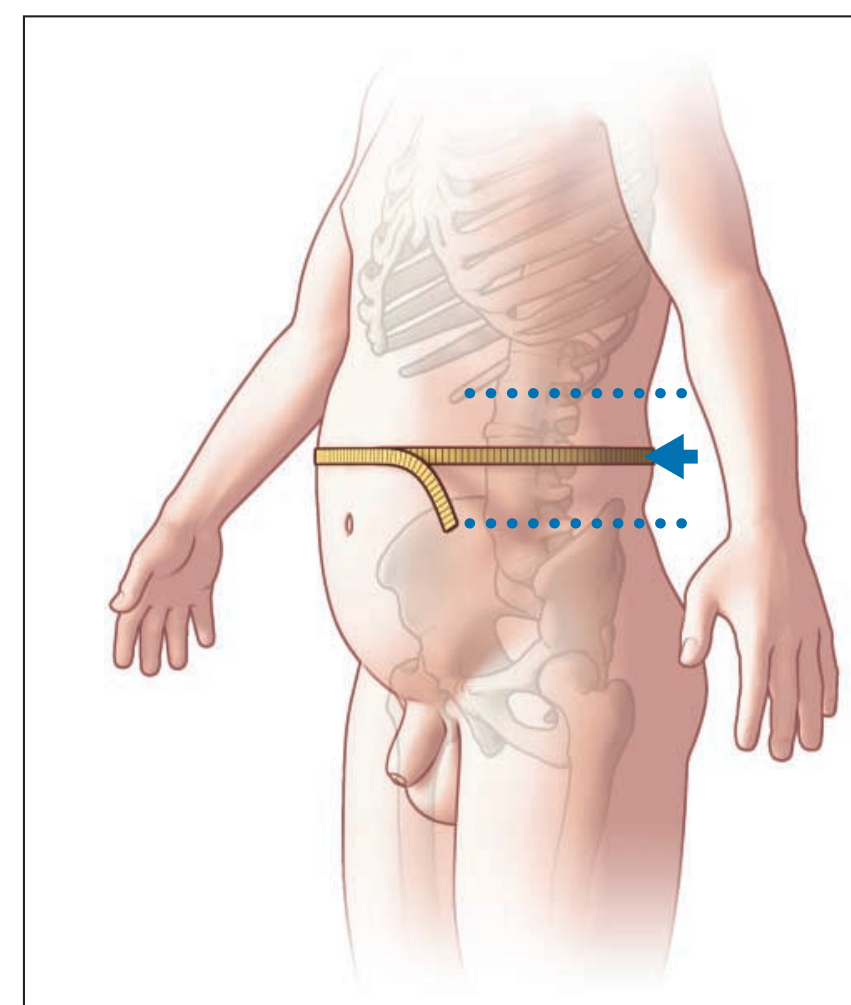

- A measuring tape is placed around the trunk, at a point midway between the lower costal margin and the iliac crest, while the patient is standing with feet about 25-30 cm (10-12 in) apart.

- The measuring tape is fit snugly around the abdomen but without compressing underlying soft tissues.

- The waist circumference is recorded to the nearest $0.5 \mathrm{~cm}$ $(1 / 4$ in) at the end of a normal expiration.

Fig. 2: Measuring waist circumference.

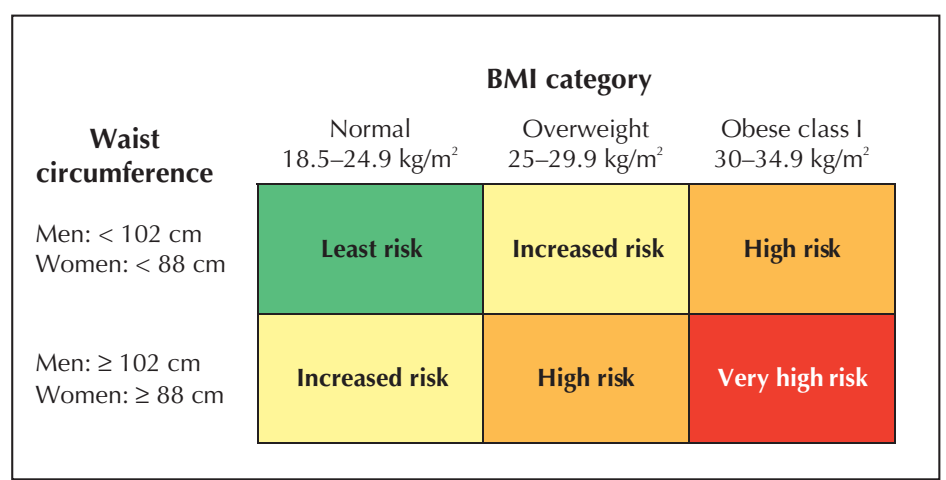

Fig. 3: Applying BMI and waist circumference measurements to assess a patient's risk of health problems. 
Table 2: Effect of increased waist circumference* on disease risk when considered in addition to BMI category

\begin{tabular}{|c|c|c|c|c|c|c|}
\hline \multirow[b]{3}{*}{ Disease } & \multicolumn{6}{|c|}{ BMI category; adjusted odds ratio (95\% confidence interval) $†$} \\
\hline & \multicolumn{2}{|c|}{$\begin{array}{c}\text { Normal } \\
\text { BMI } 18.5-24.9 \mathrm{~kg} / \mathrm{m}^{2}\end{array}$} & \multicolumn{2}{|c|}{$\begin{array}{c}\text { Overweight } \\
\text { BMI } 25-29.9 \mathrm{~kg} / \mathrm{m}^{2}\end{array}$} & \multicolumn{2}{|c|}{$\begin{array}{c}\text { Obese class I } \\
\text { BMI } 30-34.9 \mathrm{~kg} / \mathrm{m}^{2}\end{array}$} \\
\hline & Women & Men & Women & Men & Women & Men \\
\hline Hypertension & $1.9(1.3-2.8)$ & $2.3(0.6-8.7)$ & $2.0(1.4-3.0)$ & $1.5(1.1-2.0)$ & $15.9(4.2-60.3)$ & $1.1(0.4-3.0)$ \\
\hline Metabolic syndrome & $1.8(1.1-2.9)$ & $0.7(0.1-3.7)$ & $2.2(1.2-3.9)$ & $2.1(1.5-3.2)$ & $28.6(3.7-220.2)$ & $2.9(1.3-6.8)$ \\
\hline
\end{tabular}

*Increased waist circumference $=$ values of $\geq 102 \mathrm{~cm}$ in men and $\geq 88 \mathrm{~cm}$ in women. Subjects with waist circumferences below these values were used for the reference group.

†Adjusted for age, race, physical activity, smoking, alcohol intake and poverty-income ratio.

Adapted, with permission, from Arch Intern Med 2002;162:2074-9. ${ }^{2}$ Copyright $(2002$ American Medical Association.

loss may be a more useful means of determining health risk in elderly people.

Non-white people: Although the body weight classification can be applied to all ethnic groups in Canada, health care providers should be aware of limitations in applying this classification to non-white people. A recent study involving Asian people suggested that BMI cutoffs for overweight and obesity start at $23 \mathrm{~kg} / \mathrm{m}^{2}$ and $27 \mathrm{~kg} / \mathrm{m}^{2}$ respectively. ${ }^{5}$ For a given BMI range and waist circumference level, black people appear to be at lower risk of health problems than white people, which suggests the need for higher cutoff levels for BMI and waist circumference to identify increased risk in black populations. In Canadian First Nations and Inuit populations, obesity and type 2 diabetes are major health problems, with over $50 \%$ of Aboriginal people having one of these conditions. ${ }^{6}$ Whether the BMI and waist circumference cutoffs used for the general population are appropriate for Aboriginal populations requires additional research.

People with bealthy lifestyle habits: The BMI and waist circumference should be applied with caution in people who are physically active or have other healthy lifestyle habits, because these factors mitigate the risk associated with an increased $\mathrm{BMI}$ or waist circumference.

\section{A suggested 3-step approach to using the BMI and waist circumference in clinical practice}

1. Periodic BMI and waist circumference measurement: Measurement of the BMI and waist circumference should be part of a routine health assessment to screen for overweight and obesity. Measurements should be taken at least every 2 years.

2. Risk assessment: The assessment of a patient's risk of health problems should be based on his or her BMI and waist circumference as well as other determinants of risk (e.g., presence or absence of obesity-related disease, lifestyle habits) to establish the person's overall risk profile.

3. Assessment of need for interventions: The patient's overall risk profile will, in turn, determine whether lifestyle interventions (e.g., balanced diet, physical activity), weight loss interventions (e.g., dietary therapy) and drug therapy (e.g., antihypertensive or lipid-lowering drugs) are warranted to reduce his or her risk of health problems.
James D. Douketis

St. Joseph's Hospital

Department of Medicine

McMaster University

Hamilton, Ont

Gilles Paradis

McGill University Health Centre

Montréal, Que.

Heather Keller

Department of Family Relations

and Applied Nutrition

University of Guelph

Guelph, Ont.

Chantal Martineau

Health Canada

Ottawa, Ont.

For the Expert Working Group on the Canadian Guidelines for Body Weight Classification in Adults

\section{References}

1. Katzmarzyk PT. The Canadian obesity epidemic, 1985-1998. CMA7 2002;166(8):1039-40.

2. Janssen I, Katzmarzyk PT, Ross R. Body mass index, waist circumference, and health risk: evidence in support of current National Institutes of Health guidelines. Arch Intern Med 2002;162:2074-9.

3. Hu FB, Willett WC, Li T, Stampfer MJ, Colditz GA, Manson JE. Adiposity as compared with physical activity in predicting mortality among women. N Engl F Med 2004;351:2694-703.

4. Eckel RH, Krauss RM; for the AHA Nutrition Committee. American Heart Association call to action: obesity as a major risk factor for coronary heart disease. Circulation 1998;97:2099-100.

5. WHO Expert Consultation. Appropriate body-mass index for Asian populations and its implications for policy and intervention strategies. Lancet 2004;363:157-63

6. Young TK, Reading J, Elias B, O'Neil JD. Type 2 diabetes mellitus in Canada's First Nations: status of an epidemic in progress. CMA7 2000;163(5):561-6. 